\title{
TEMPERATURE DEPENDENCE OF IONIZATION RATES IN $\mathrm{Al}_{x} \mathrm{Ga}_{1-x} \mathrm{As}^{*}$
}

\author{
C. YEH and S. N. SHABDE \\ Electron Physics Laboratory, Department of Electrical Engineering. The University of Michigan, \\ Ann Arbor, Michigan, 48104 U.S.A.
}

(Received 17 July 1970; in revised form 9 November 1970)

\begin{abstract}
The ionization rates in $\mathrm{Al}_{x} \mathrm{Ga}_{1-x} \mathrm{As}$ have been measured in a temperature range from $77^{\circ} \mathrm{K}$ to $373^{\circ} \mathrm{K}$ for samples with various $\mathrm{Al}$ content. The results showed that the ionization rates decrease with both the $\mathrm{Al}$ content and temperature at a given electric field. A deviation from $\exp \left(1 / E^{2}\right)$ field dependence is observed for the sample with the highest Al content at lower temperatures. By fitting the data into the modified Baraff's plot, $\lambda$, the optical phonon mean free path was determined at four different temperatures. Assuming $\lambda=\lambda_{0} \tanh \left(\epsilon_{r} / 2 k T\right), \lambda_{0}$, the high-energy low-temperature asymptotic limit of the mean free path was evaluated. The temperature dependence of $\lambda$ and the compositional dependence of $\lambda_{0}$ are discussed.
\end{abstract}

Résumé-Les taux d'ionisation dans le $\mathrm{Al}_{x} \mathrm{Ga}_{1-x} \mathrm{As}$ ont été mesurés dans une gamme de températures de $77^{\circ} \mathrm{K}$ à $373^{\circ} \mathrm{K}$ pour des échantillons de teneur en Al variable. Les résultats ont montré que les taux d'ionisation décroissent avec la teneur en $\mathrm{Al}$ et avec la température à un champ électrique donné. Une déviation de la dépendance de champ exp $\left(I / E^{2}\right)$ est observée pour l'échantillon ayant la teneur en $\mathrm{Al}$ la plus élevée à basse température. En plaçant les données dans la cote modifiée de Baraff, $\lambda$, le parcours libre moyen du phonon optique a été déterminé à quatre températures différentes. En supposant $\lambda=\lambda_{0}$ tanh $\left(\epsilon_{r} 2 k T\right), \lambda_{0}$, la limite asymptotique de haute énergie et basse température de parcours libre moyen a été évaluée. La dépendance de $\lambda$ sur la température et la dépendance compositionelle de $\lambda_{0}$ sont discutées.

Zusammenfassung - Die Ionisationsraten in $\mathrm{Al}_{x} \mathrm{Ga}_{1-x}$ As warden im Bereich von $77 \mathrm{~K}$ bis $373 \mathrm{~K}$ für Proben mit unterschiedlichem Al-Gehalt bestimmt. Das Ergebnis zeigt, daß die Ionisationsraten bei konstantem elektrischen Feld sowohl mit zunehmender Al-Konzentration als auch mit der Temperatur abnehmen.

Proben mit dem höchsten Al-Gehalt zeigen bei niedrigen Temperaturen eine Abweichung von der Feldabhängigkeit nach exp $\left(1 / E^{2}\right)$. Durch Anpassen einer modifizierten Baraff-Auftragung an die Ergebnisse wird die mittlere freie Weglänge $\lambda$ optischer Phononen bei vier Temperaturwerten ermittelt. Unter der Annahme eines Gesetzes $\lambda=\lambda_{0} \tanh \left(\epsilon_{r} / 2 k T\right)$ wurde $\lambda_{0}$, als Grenzwert für den Fall hoher Energie und niedriger Temperatur bestimmt. Die Temperaturabhängigkeit von $\lambda$ und die Abhängigkeit des $\lambda_{0}$ von der Kristallzusammensetzung werden diskutiert.

\section{INTRODUCTION}

AvALANCHE multiplication for electrons and holes in semiconductors have been studied by many investigators. The secondary ionization rates for electrons and holes have been measured by Miller in $\mathrm{Ge}[1]$, Lee $e t$ al. in $\mathrm{Si}[2]$, Logan and White in $\mathrm{GaP}[3]$ and Logan and Sze in Ge and GaAs[4]. The experimental results have been satisfactorily

\footnotetext{
*'This work was partially supported by the Electronics Research Center of the National Aeronautics and Space Administration under Grant No. NGL 23-005-183. It was also partially supported by a grant from the Rackham School of Graduate Studies at The University of Michigan.
}

explained by Baraff's theory $[5,6]$. The temperature dependence of the ionization rates in Si and Ge was studied by Crowell and Sze [7]. They considered both the generation and absorption of optical phonons. A similar study has also been made in GaAs by Chang and Sze[8]. Recently the compositional dependence of the ionization rates in the mixed III-V compound, $\mathrm{Al}_{x} \mathrm{Ga}_{1-x} \mathrm{As}$, was reported by Shabde and Yeh [9]. The temperature dependence of the ionization rates in this material are presented here.

\section{EXPERIMENT}

$p-n$ junction diodes of $\mathrm{Al}_{x} \mathrm{Ga}_{1-x}$ As with various 
amounts of Al content were supplied by the RCA Laboratories. The diodes were mounted in varactordiode packages. The diodes were selected on the basis of their $C-V$ and breakdown characteristics at room temperature. All the selected diodes showed a $\log C$ vs. $\log V$ plot which was a straight line having a slope of $-\frac{1}{2}$, indicating that the junction is abrupt. The junction width is of the order of $10^{-5} \mathrm{~cm}$. These diodes were further examined for their breakdown characteristics. Those with clear and sharp breakdown characteristics, which indicated that the microplasma formation was minimum, were selected. The breakdown voltages of these diodes are also consistent and are within $\pm 0 \cdot 1 \mathrm{~V}$ with that calculated from the doping densities. The area of the diodes was kept small; typically, $5 \times 5$ mil square in order to reduce the probability of microplasma formation. Photoresponse and $C-V$ measurements were made for the diodes over a temperature range from $77^{\circ} \mathrm{K}$ (liquid nitrogen) to $373^{\circ} \mathrm{K}$ (boiling water) with intermediate temperatures at $200^{\circ} \mathrm{K}$ (alcohol in dry ice) and $300^{\circ} \mathrm{K}$ (room temperature), respectively. To facilitate the measurement at various temperatures. the diode was mounted on the top end of a heavy copper rod, $1 \mathrm{in}$. in diameter and 10 in. long. The rod was immersed in a thermal flask which was filled with the appropriate coolant. A thermocouple attached directly to the diode holder was used to measure the device temperature. The top end of the rod, including the diode. was enclosed in a glass cup into which dry nitrogen gas was kept flowing to avoid moisture condensation. The diode junction was exposed to a chopped light source and the photoresponse of the diode was measured by a wave analyzer whose output was plotted as a function of the reverse bias voltage on an $x-y$ recorder.

\section{RESULTS AND DISCUSSIONS}

Data were processed to obtain the multiplication factor $M$ from which the ionization rate $\alpha$ was computed [10]. Ionization rates for electrons and holes are assumed equal[4]. A plot of $\alpha$ vs. 1/ $E_{m}{ }^{2}$ on semilogarithmic paper resulted in straight lines indicating the ionization coefficient to be of the form

$$
\alpha=A \exp \left[-\left(\frac{b}{E_{m}}\right)^{p}\right]
$$

where $A$ and $b$ are constants and $E_{m}$ is the maximum electric field at the junction.

It was observed that the straight-line relationship between $\alpha(E)$ and $1 / E_{m}{ }^{2}$ holds true for all samples at all temperatures with the exception of the sample with the highest Al content (12 per cent). The data for this sample are plotted in Fig. 1. The deviation from a straight line increases with decreasing temperature and is particularly noticeable at $100^{\circ} \mathrm{K}$. This point will be discussed further in a later paragraph.

Data for all the samples were plotted to fit the appropriate Baraff curve. The three material parameters used to fit the ionization rate data are the ionization energy $\epsilon_{i}$, the optical phonon energy $\epsilon_{r}$ and the carrier mean free path for optical phonon generation $\lambda$. To account for the effect of both the optical phonon generation and absorption. rather than generation alone, the average energy lost per collision $\left\langle\epsilon_{r}\right\rangle$ was used instead of $\epsilon_{r}$. $\left\langle\epsilon_{r}\right\rangle$ was calculated by the following expression [11]

$$
\left\langle\epsilon_{r}\right\rangle=\epsilon_{r} \tanh \left(\epsilon_{r} / 2 k T\right) .
$$

The value of $\epsilon_{r}$ for GaAs at room temperature was used in this equation. To avoid the need for a theoretical determination of the energy threshold the practice of Logan et al. [10] and others has been adopted to determine both $\epsilon_{i}$ and the mean free path $\lambda$ from a fit of Baraff's theory. A typical plot of the Baraff curves for one sample of $\mathrm{Al}_{x} \mathrm{Ga}_{1}{ }_{x} \mathrm{As}$ at various temperatures is shown in Fig. 2 , in which $\alpha \lambda$ is plotted as a function of $\epsilon_{i} / e E \lambda$. The results of the curve fitting are summarized in Table 1 . It is found that $\lambda$ decreases with increasing $\mathrm{Al}$ content and increasing temperature. In the table $\epsilon_{i}$ is given in terms of $\left\langle\epsilon_{r}\right\rangle / \epsilon_{i}$ for best fitting. The parameter $\lambda_{0}$, the low-temperature limiting value of the mean free path, was also evaluated and tabulated along with $\lambda . \lambda$ and $\lambda_{10}$ are related by the expression [11]

$$
\lambda=\lambda_{0} \tanh \left(\epsilon_{r} / 2 k T\right) .
$$

Calculated values of $\lambda_{0}$ remain practically constant with temperature as is expected. $\lambda_{0}$ thus can be considered as a material constant for the sample. The fact that $\lambda_{0}$ decreases with increasing $\mathrm{Al}$ content but is independent of temperature, suggests that the mechanism responsible for this change is presumably related to the electron-optical phonon interaction. 


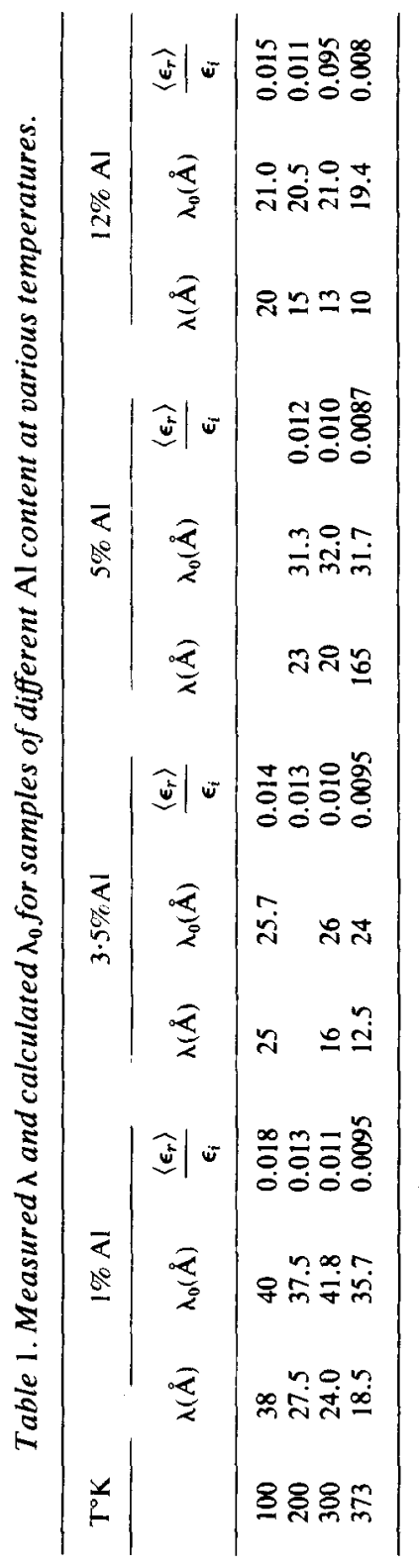




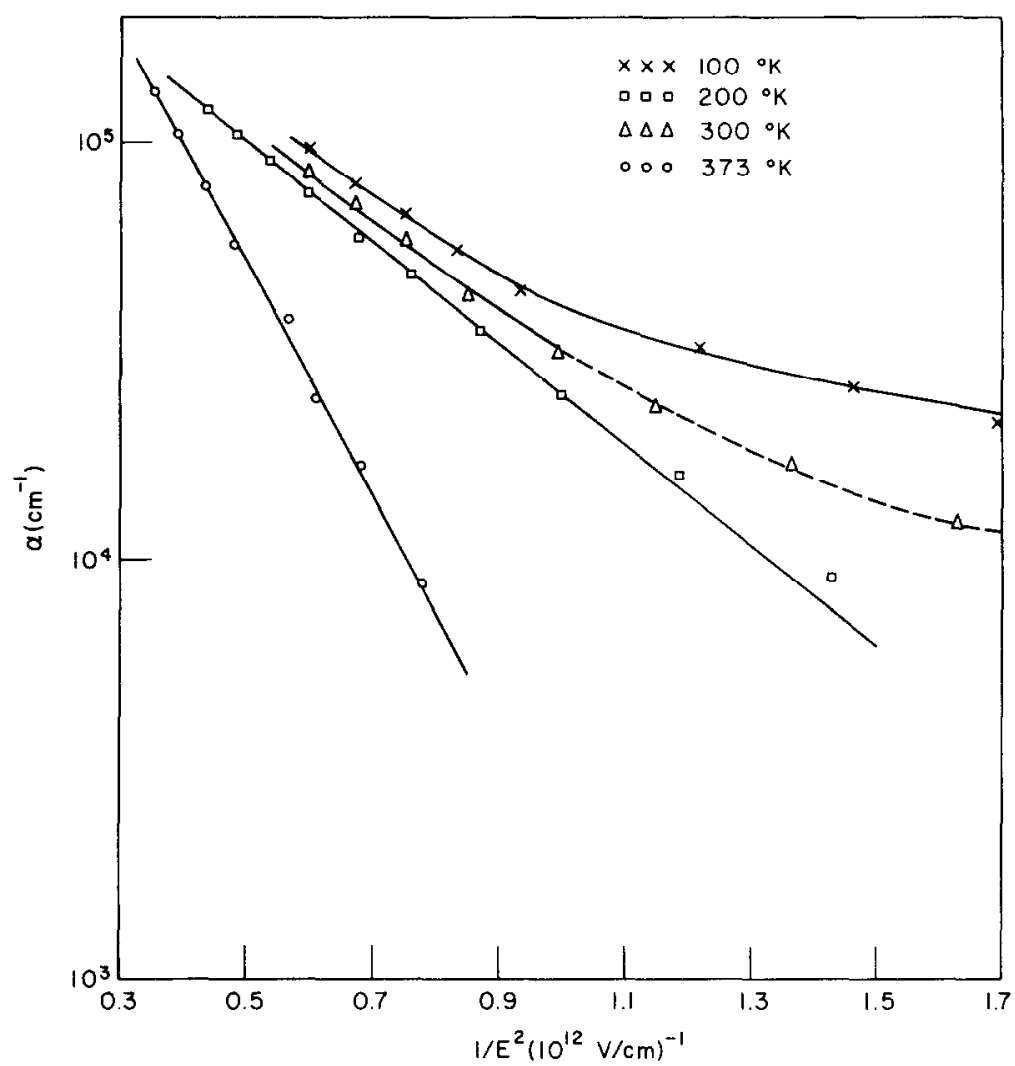

Fig. 1. Ionization Rate $\alpha$ as a function of $1 / E_{m}^{2}$ for $\mathrm{Al}_{x} \mathrm{Ga}_{1-x} \mathrm{As}(x=0.12)$ at various temperatures.

The deviation from a straight line in the $\alpha$ vs. $1 / E_{m}^{2}$ plots for the sample with the high $\mathrm{Al}$ content will now be discussed. The straight-line relationship implies that the electric field within the junction is high enough to be in the range of Wolff's high-field approximation[12]. Chynoweth [13] gave a criterion for the validity of Wolff's high-field theory as

$$
\frac{e E \lambda}{\epsilon_{r}} \geqq 3 .
$$

Considering both the optical phonon generation and absorption, i.e., using $\left\langle\epsilon_{r}\right\rangle$ in place of $\epsilon_{r}$, the condition becomes

$$
\frac{e E \lambda_{0}}{\epsilon_{r}} \geqq 3
$$

The electric field at which the ionization rate becomes measurable decreases with decreasing temperature. Also, as observed in this work, $\lambda_{0}$ decreases with increasing $\mathrm{Al}$ concentration. Thus, the above criterion for Wolff's theory is most likely to be violated for the sample with the highest $\mathrm{Al}$ content at the lowest temperature. As seen in Fig. 1 , for the sample with 12 per cent $\mathrm{Al}$, a deviation from Wolff's theory occurs in data obtained with $T<200^{\circ} \mathrm{K}$. Table 2 shows the quantity $e E \lambda_{0} / \epsilon_{r}$ evaluated at the lowest electric field at each temperature for different $\mathrm{Al}$ concentrations. It appears that all of these quantities satisfy the criterion expressed in equation 5 , including the lowest ratio of 3.3 for 12 per cent $\mathrm{Al}$ at $100^{\circ} \mathrm{K}$. However, the assumption that $\epsilon_{r}=0.036 \mathrm{eV}$ (the value for pure GaAs) and remains unchanged for all $\mathrm{Al}$ content may not be exactly true for high $\mathrm{Al}$ 


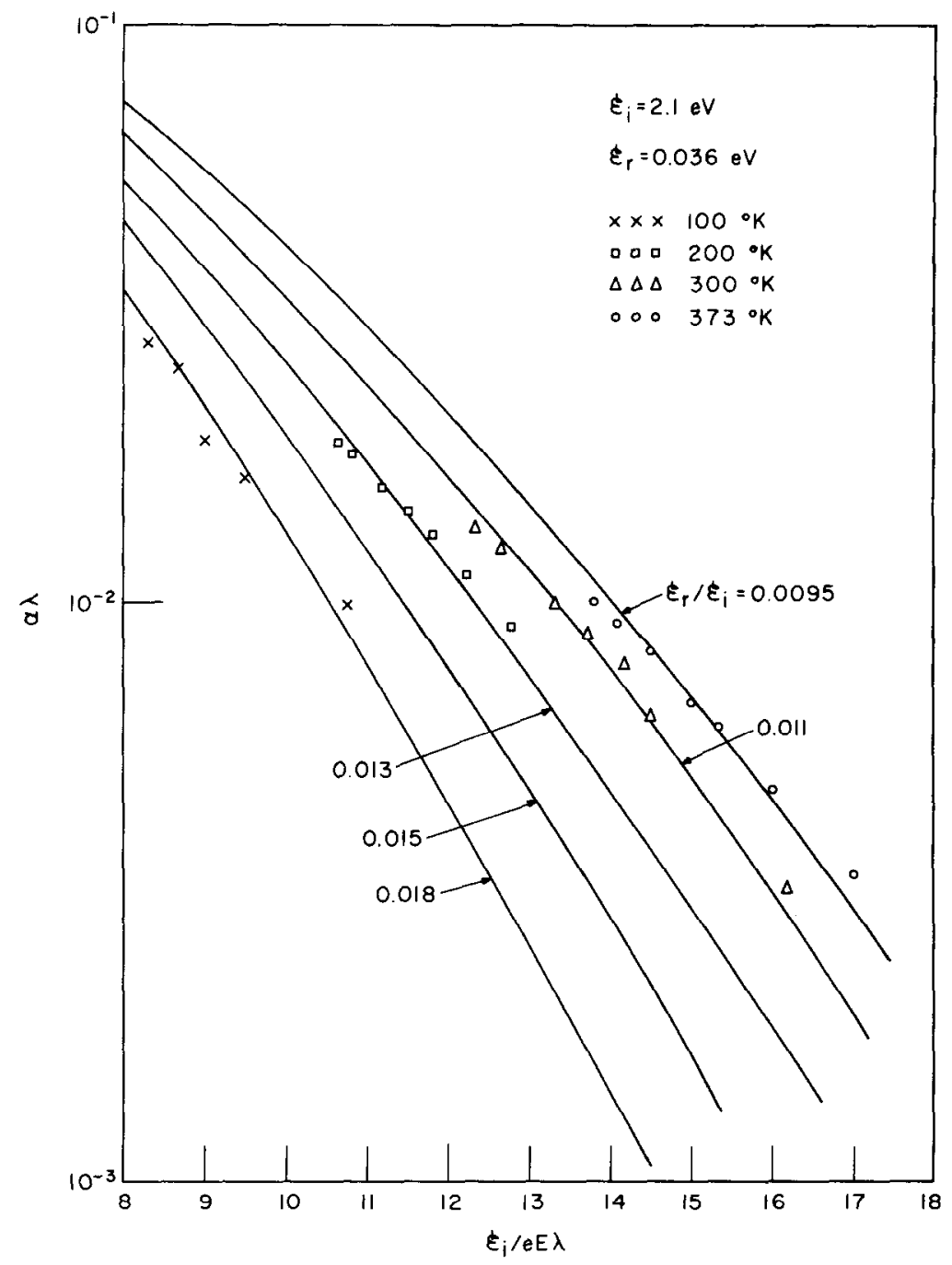

Fig. 2. Baraff plot for $\mathrm{Al}_{x} \mathrm{Ga}_{1-x} \mathrm{As}(x=0.01)$ at various temperatures

Table 2. Ratio of $e E \lambda_{0} / \epsilon_{r}$ for the lowest electric field of the samples with different $\mathrm{Al}$ content at various temperatures.

\begin{tabular}{lcccc}
\hline \multicolumn{5}{c}{$e E \lambda_{0} / \epsilon_{r}$} \\
\hline \multirow{2}{*}{ Al(\%) } & $100^{\circ} \mathrm{K}$ & $200^{\circ} \mathrm{K}$ & $300^{\circ} \mathrm{K}$ & $373^{\circ} \mathrm{K}$ \\
\cline { 2 - 5 } 1 & 4.5 & 6.2 & 5.1 & 6.5 \\
3.5 & 4.2 & 5.1 & 4.7 & 6.0 \\
5 & & 5.1 & 5.1 & 6.6 \\
12 & 3.2 & 4.0 & 4.3 & 6.4 \\
\hline
\end{tabular}

content. An increase in $\epsilon_{r}$ of about 10 per cent will shift the lowest value of $e E \lambda_{0} / \epsilon_{r}$ below three. In a recent paper, Ilgems and Pearson [14] studied the infrared lattice-vibration spectra of $\mathrm{Al}_{x} \mathrm{Ga}_{1-x} \mathrm{As}$ mixed crystals as a function of the composition. Their results show an increase in the frequency of the AlAs-like mode with increasing Al content. This finding suggests the possibility that $\epsilon_{r}$, the average energy loss in the electron-optical phonon scattering, might increase with increasing $\mathrm{Al}$ content. 
Acknowledgment-The authors are grateful to the RCA Laboratories and in particular to Dr. H. Kressel for his valuable discussions and to Mr. F. Z. Hawrylo for supplying the diodes. They also wish to thank Professor G. I. Haddad for his help and encouragement during these investigations.

\section{REFERENCES}

1. S. L. Miller, Phys. Rev. 99, 1234 (1955).

2. C. A. Lee, R. A. Logan, R. L. Batdorf, J. J. Kleimack and W. Wiegmann, Phys. Rev. 134, A761 (1964).

3. R. A. Logan and H. C. White, J. appl. Phys. 36, 3945 (1965).

4. R. A. Logan and S. M. Sze, J. Phys. Soc. Japan 21, Supplement, 434 (1966).

5. G. A. Baraff, Phys. Rev. 128, 2507 (1962).

6. G. A. Baraff, Phys. Rev. 133, A26 (1964).
7. C. R. Crowell and S. M. Sze, Appl. Phys. Lett. 9, 242 (1966).

8. Y. J. Chang and S. M. Sze, J. appl. Phys. 40, 5393 (1969).

9. S. N. Shabde and C. Yeh, J. appl. Phys. 41, 4743 (1970).

10. R. A. Logan, A. G. Chynoweth and B. G. Cohen, Phys. Rev. 128, 2518 (1962).

11. C. R. Crowell and S. M. Sze, Appl. Phys. Lett. 9, 242 (1966).

12. P. A. Wolff, Phys. Rev. 95, 1415 (1954).

13. A. G. Chynoweth, in Semiconductors and Semimetals, Vol. 4, Physics of III-V Compounds (R. K. Willardson and A. C. Beer, Ed), p. 263, Academic Press, New York (1968).

14. M. Ilgems and G. L. Pearson, Phys. Rev. Bl, 1576 (1970). 